\title{
Employee engagement, organisational performance and individual well-being: exploring the evidence, developing the theory
}

\author{
Catherine Truss $^{\mathrm{a} *}$, Amanda Shantz ${ }^{\mathrm{b}}$, Emma Soane $^{\mathrm{c}}$, Kerstin Alfes $^{\mathrm{d}}$ and Rick Delbridge ${ }^{\mathrm{e}}$ \\ ${ }^{a}$ Kent Business School, University of Kent, Kent, UK, ${ }^{b}$ School of Human Resource Management, \\ York University, Toronto, ON, Canada; ${ }^{c}$ Department of Management, London School of Economics \\ and Political Science, London, UK; ${ }^{d}$ Department of Human Resource Studies, Tilburg University, \\ Tilburg, The Netherlands; ${ }^{e}$ Cardiff Business School, Cardiff University, Cardiff, UK
}

The development of mainstream human resource management (HRM) theory has long been concerned with how people management can enhance performance outcomes. It is only very recently that interest has been shown in the parallel stream of research on the link between employee engagement and performance, bringing the two together to suggest that engagement may constitute the mechanism through which HRM practices impact individual and organisational performance. However, engagement has emerged as a contested construct, whose meaning is susceptible to 'fixing, shrinking, stretching and bending'. It has furthermore not yet been scrutinised from a critical HRM perspective, nor have the societal and contextual implications of engagement within the domain of HRM been considered. We review the contribution of the seven articles in this special issue to the advancement of theory and evidence on employee engagement, and highlight areas where further research is needed to answer important questions in the emergent field that links HRM and engagement.

Keywords: employee engagement; human resource management; performance; wellbeing

\section{Introduction}

Researchers within the mainstream human resource management (HRM) field have long been concerned with the question of how the management of people can lead to improved organisational performance outcomes (Huselid 1995). Indeed, the quest to understand and operationalise the HRM-performance link has come to be seen as the overriding purpose of strategic human resource management (SHRM; Delbridge and Keenoy 2010). It was therefore no doubt with some degree of despondency that researchers and practitioners alike read Guest's (2011, p. 11) recent conclusion that 'we are still in no position to assert with any confidence that good HRM has an impact on organisation performance'. The area remains beset with problems of theory, methodology and data (Boselie, Dietz and Boon 2005).

One of the main challenges within this stream of research has been the identification of the mechanism(s) by which HRM gives rise to improved performance at either the individual or the organisational level. Early studies in the field tended to focus on the macro level and to propose a direct or linear relationship between the two, but lacked convincing theoretical explanations (Guest 2011). Recent research has adopted a social exchange framework and quantitative methodologies at the micro level to suggest that the relationship is most likely mediated by attitudinal variables. For example, it has been proposed that positive perceptions of HRM systems may give rise to high levels of commitment and job

\footnotetext{
*Corresponding author. Email: k.truss@kent.ac.uk
} 
satisfaction which, in turn, are linked with enhanced citizenship behaviours, lower intent to quit, reduced absence levels and improved task performance (Allen, Shore and Griffeth 2003; Den Hartog, Boselie and Paauwe 2004; Kuvaas 2008; Conway and Monks 2009; Snape and Redman 2010). However, the findings within this stream of research have so far also been largely inconclusive (Alfes, Truss, Soane, Rees and Gatenby in press).

In parallel with the development of the SHRM field, researchers in psychology and social psychology have been concerned with exploring how the attitudinal construct of employee engagement could help explain individual performance outcomes. As we shall see below, definitions of engagement have varied considerably, but evidence has accumulated on the basis of quantitative studies to suggest that high levels of engagement are associated with high levels of performance, citizenship behaviour and individual wellbeing (Christian, Garza and Slaughter 2011; Hakanen and Schaufeli 2012; Soane 2013).

Given the shared focus of these two streams of research, it is perhaps surprising that it is only now that researchers within the HRM field are starting to recognise the relevance of engagement for their endeavours, and studies linking the two are just emerging (Truss, Alfes, Delbridge, Shantz and Soane 2013b). For instance, earlier papers published in this journal have examined the link between job design and engagement (Salanova and Schaufeli 2008), and between justice and engagement (Biswas, Varma and Ramaswami 2012). There has been one study that has begun to set engagement strategies within the context of wider discussions of the employment relationship (Townsend, Wilkinson and Burgess 2013); elsewhere, scholars in the USA have examined engagement through a human resource development lens (Shuck and Reio 2011; Shuck and Rocco 2013). Initial quantitative research exploring the link between HRM, engagement, performance and citizenship behaviours has also shown some promise (Alfes, Shantz, Truss and Soane 2013; Alfes et al. in press).

Given the previously inconclusive nature of prior studies seeking to link HRM with performance, we ask whether engagement is perhaps the 'promised land' where we finally can demonstrate that HRM leads to higher levels of performance, or whether the incorporation of engagement into studies of HRM will replicate or even exacerbate the existing uncertainties and tensions prevalent in the SHRM field. The concern with linking SHRM and performance has been challenged by critical scholars for its unitarist and acontextual view of organisational life, and one of the goals of this editorial and a number of papers in this special issue is to build on these views and provide one of the first assessments of engagement from a critical HRM perspective (Delbridge and Keenoy 2010).

In this paper, we first examine the development and application of the construct of engagement, and consider its locus in relation to wider debates within the HRM field. We then introduce the seven papers that form this special issue and highlight their contribution to the advancement of theory and practice, before concluding with some insights into the potential future direction for research in the field. This editorial, and the papers that follow, seek to contribute to the development of the construct of 'employee engagement' as it evolves within HRM, as well as to advance debates around some of the key questions concerning engagement from the perspective of scholars working within positivist, as well as critical paradigms, to help advance our understanding of the underlying principles and the practice of engagement.

\section{Engagement: HRM's 'new best friend'?}

Engagement first entered the academic lexicon in the social psychological work of Kahn (1990, p. 702), who proposed that personal engagement occurs when 'people bring in or leave out their personal selves during work-role performances'. These behaviours are 
defined by the extent to which people employ physical, cognitive and emotional degrees of themselves during work-role performances. As such, engaged employees express their authentic selves through physical involvement, cognitive awareness and emotional connections. Conversely, disengaged employees 'uncouple' themselves from their roles, suppressing personal involvement in physical, cognitive and emotional aspects of work. Kahn used the term 'personal engagement' in his writings, and argued that the authentic expression of self that occurs during experienced engagement is psychologically beneficial for the individual.

Shuck (2011) later classified Kahn's theory within a broader typology of engagement theories as a need-satisfying approach, and argued that three alternative approaches to engagement were evident within the literature. The second approach is the burnoutantithesis view on engagement developed by Maslach and Leiter (1997), who propose that engagement and burnout are opposite ends of a continuum. Although burnout features exhaustion, cynicism and lack of accomplishment, engagement is associated with energy, involvement and efficacy. Alternatively, Schaufeli, Salanova, Gonzalez-Roma and Bakker (2002, p. 74) argue that engagement is a distinct concept defined as 'a positive, fulfilling, work-related state of mind that is characterised by vigor, dedication and absorption'. In their work, the Utrecht team refer to 'work engagement' rather than 'personal engagement' and propose that engaged workers are likely to perform better than their disengaged peers (Schaufeli 2013).

The third approach, the satisfaction-engagement approach, was developed by the survey firm Gallup, and taken to mean 'an individual's involvement and satisfaction with, as well as enthusiasm for, work' (Harter, Schmidt and Hayes 2002, p. 269). In this sense, the term 'employee engagement' better encapsulates the focus of the construct. Finally, Shuck (2011) identifies the 'multidimensional' approach to engagement, which is associated with the work of Saks (2006), who differentiates between 'job engagement' and 'organisational engagement', thus suggesting that engagement can have multiple foci, similar to commitment.

Shuck's (2011) typology provides an insight into how engagement has been conceptualised to date. There appears to be an agreement that engagement is a positive state of mind, and studies have shown that engagement levels are susceptible to influence from contextual and interpersonal factors (Kahn and Heaphy 2013; Schaufeli 2013).

However, Shuck's typology also highlights the diversity of ways in which engagement has been defined and operationalised, further exacerbated by what Guest (2013) terms the 'consultancy approach' to engagement, associated with the satisfaction-engagement dimension of Shuck's typology. Here, the concept of 'engagement' is often used as a catchall that captures a range of work-related attitudes, including job satisfaction, alongside perceptions of various organisational behaviours such as leadership, voice and involvement, leading Guest (2013) to question whether engagement lacks construct validity. For example, MacLeod and Clarke (2009, p. 9) in their report to the UK government define engagement as 'a workplace approach designed to ensure that employees are committed to their organisation's goals and values, motivated to contribute to organisational success, and are able at the same time to enhance their own sense of well-being'. This definition suggests that engagement may mean a variety of things, and not just a positive state of mind. As Keenoy (2013) further notes, many consulting firms now organise their products and services around the development and enhancement of 'employee engagement', suggesting that the term may have been hijacked by those with different agendas.

This brief review of the emergence and application of the engagement construct, which has been the subject of more extensive discussions elsewhere (Keenoy 2013; Schaufeli 
2013), is resonant of the discursive dynamics identified by Lombardo, Meier and Verloo (2010, p. 107) in the context of meanings of 'gender equality', in that engagement has been subject to 'fixing, shrinking, stretching and bending'. Engagement has been 'fixed', in the sense that it is now an established term in both managerial and academic discourses, and appears unlikely to be abandoned as a fad (Guest 2013). As Lombardo et al. (2010, p. 108) note, 'fixing' can also lead to the initiation of a process of contestation, whereby meanings become challenged. We can observe this occurring in relation to engagement as it enters the HRM domain and becomes the focus of critical HRM scholars questioning engagement's unitarist and managerialist underpinnings (Jenkins and Delbridge 2013; Keenoy 2013; Purcell 2013).

It has also been susceptible to 'shrinking' in that as the field develops, engagement appears to be shedding its roots as a multi-faceted meaningful individual experience embedded within work and wider societal contexts (Kahn 1990), to be defined within a positivist framework as a malleable state that is solely measurable via quantitative techniques (cf. Halford and Strangleman 2009). Equally, we have witnessed the 'stretching' of engagement in multiple directions as researchers extend the focus (Saks 2006) and breadth (Harter et al. 2002) of engagement into new domains, blurring the boundaries between engagement and other similar constructs.

Perhaps most significantly, we have seen the 'bending' of engagement to the policy, professional, consultancy and managerialist agendas of those observing that a link between high levels of engagement and high levels of performance might provide justification for proselytizing engagement as the 'new best way' to manage people (Keenoy 2013). This line of reasoning has obvious parallels with debates about the link between bundles of 'best practice' HRM such as high-commitment, high-performance or high-involvement HR strategies and high levels of performance (Wright, Snell and Dyer 2005; Truss, Mankin and Kelliher 2012).

Although low levels of engagement, or disengagement, have been viewed within the literature as problematic for individuals in that they have been associated with impaired well-being, and for organisations, as they are linked with low levels of performance (Christian et al. 2011), George (2011, p. 53) argues that high levels of engagement may be equally problematic: 'the costs of high work engagement for employees deserve far greater attention than they have received to date and question to what extent high engagement is always such a positive experience for employees'. In particular, she cites rising levels of productivity associated with work intensification and income inequality, and questions the legitimacy of organisations deliberately soliciting high engagement levels but failing to reward workers appropriately. An additional consideration is the probability of impaired work-life balance for engaged workers (Halbesleben 2011). Thus, engagement may not always be uniformly beneficial to employees.

Also of note is that little consideration has been given to equality and diversity in relation to engagement; for instance, Halbesleben (2011) shows that workers with attention deficit hyperactivity disorder or chronic illness may be less able to achieve high levels of engagement, and the literature remains silent on how engagement interacts with gender and ethnicity, thus opening a significant debate on equality and engagement that is of relevance both to psychologists and to HRM scholars. This has parallels with the HRMperformance debate which equally fails to address how HRM relates to issues of diversity (Truss 1999).

Although we are now witnessing a rapidly expanding interest in engagement amongst HRM scholars, it is only just beginning to be subject to the same critical scrutiny as HRM (Guest 2013; Jenkins and Delbridge 2013; Keenoy 2013; Purcell 2013). Engagement's 
roots within positive psychology (Youssef-Morgan and Bockorny 2013) suggest that the concept potentially fits well within the discourse of what might be termed 'positive HRM', with its unitarist focus on how HRM can be harnessed to the benefit of individual and organisational performance, sidestepping the discipline's traditional roots in the socialscientific study of organisational realities (Watson 2010). Engagement demonstrates the potential to become the 'new best practice' HRM approach, with the prospect of 'high engagement HRM' becoming the dominant discourse within mainstream HRM, suggestive of its slippery and discursively constructed nature.

The development of engagement within the HRM field provides an opportunity not only to expand the existing rich seam of research on engagement as a psychological state through further studies of where, how and why engagement arises and its interrelationship with other experiences and attitudes but also to consider engagement within a societal and cultural context, and in relation to critical perspectives that account for the plurality of the employment relationship. As Delbridge and Keenoy (2010, p. 801) argue, 'the practice of management can only be understood in the context of the wider social-economic, political and cultural factors which shape - if not determine - those practices'. Such concerns are of interest and relevance to psychologically grounded studies as well, as they start to unpick in a more nuanced way the links between engagement and other constructs for diverse workers in a variety of organisational, cultural and societal settings.

\section{Contributions to the special issue}

This special issue arose out of a seminar series of the same title led by the editors and funded by the Economic and Social Research Council (RES-451-26-0807). The series comprised five seminars held in the UK from 2010 to 2013. At the time we proposed the series, although research on engagement was well established within the psychology discipline, very few HRM scholars around the world were working on the topic. Given significant levels of interest amongst the practitioner community in engagement, and its clearly central relevance to the HRM discipline, our aim was to raise awareness of engagement amongst HRM scholars, and to bring together a community of researchers and practitioners to discuss engagement within the context of HRM debates. The series has given rise to this special issue, together with an edited volume (Truss, Alfes, Delbridge, Shantz and Soane 2013a). We invited contributors to this special issue to address a range of topics around engagement, and called for papers that addressed the nature and meaning of engagement, the link between engagement and other constructs, and those that challenged the engagement construct from a critical perspective.

We received a large number of submissions to the special issue, signalling a burgeoning interest in the topic of engagement amongst HRM scholars. The seven articles that were selected following the review process represent a mixture of those that extend current debates within the engagement psychology field in novel ways, as well as those offering diverse insights grounded in critical perspectives on HRM and the employment relationship. The authors offer varying definitions and conceptualisations of 'engagement', and adopt a wide range of methodologies, from the positivist, quantitative approaches that have been prevalent in the field to date, to the qualitative, critical perspectives and those grounded in discourse analysis. Notably, some of the articles include evaluations of workplace engagement initiatives, an area of significant importance for both HRM practitioners and scholars, yet one that has hitherto been neglected within the engagement literature. This plurality of views is to be welcomed, as the discussion about engagement widens out into the HRM domain. 
The first four papers in our special issue approach engagement from a critical perspective and within the context of extant HRM debates. In the first paper, Sarah Jenkins and Rick Delbridge examine how engagement is played out in practice through two case studies of contrasting organisations. The authors suggest that these cases are illustrative of 'soft' and 'hard' approaches to engagement, a debate reminiscent of long-standing dualities within the HRM literature (Storey 1989). The cases show how efforts to foster high levels of engagement can be driven either from a will to gain competitive advantage ('hard' engagement) or, conversely, from a desire to improve working conditions and the employment relationship ('soft' engagement). A particular contribution of the paper is the light that it sheds on the role played by contextual contingencies such as environmental volatility, organisational values and culture, alongside managerial constraints and limitations. The authors sound a cautionary note against unitarist and managerialist accounts, and suggest that engagement should be viewed through a critical lens that takes account of political and cultural hegemony.

Building on related themes, Jim Arrowsmith and Jane Parker analyse the effects of an employer-led engagement initiative within New Zealand Post as it went through a period of transition involving deregulation, increased competition and significant technological changes. This longitudinal, qualitative case study sheds light on the complex nature of organisational engagement programmes that involve multiple interventions, through insights from the diverse stakeholders involved. A particular contribution of this paper is that it highlights the tensions and ambiguities that are played out through 'doing' engagement. The authors discuss the diverse engagement schemas held by various organisational actors, including HRM professionals, trades union officials, senior managers, line managers and workers, and argue that engagement is not a static, value-free construct. The authors conclude that engagement can be viewed through a neo-pluralistic lens that combines a unitarist perspective on HRM with an acknowledgement of its pluralist roots, where the HRM professional performs the role of 'change-maker' through combining a concern with performance with a concern for commitment through the engagement programme.

Helen Francis, Allan Ramdhony, Martin Reddington and Harry Staines set their study within the context of the global financial crisis and cut backs to public services. Drawing on critical HRM approaches and notions of dialogic conversational practice, they challenge the instrumental mode of reasoning that they believe underpins the notion of high-involvement HRM practices and organisational approaches to managing employee engagement. Using mixed methods, Francis and colleagues undertook case study research in two public sector organisations in the UK, and found evidence of the development of a new organisational order focused around compliance and work intensification in light of prevailing political discourses on retrenchment. They also point to the 'resigned acceptance' and ongoing resilience of staff in the face of these realities. Their study draws out four types of conversational practices that are enacted within the line manageremployee relationship and highlights the discursive role played by line managers in their daily interactions.

In a case study undertaken within a newly formed public-private partnership organisation, Stephanie Reissner and Victoria Pagan focus on engagement within the context of organisational change and communication. The authors address debates concerning the focus of engagement and suggest that, from an HRM perspective, engagement with the organisation rather than with the job may be more meaningful both in theory and in practice (Shuck 2011). In a similar way to the paper by Arrowsmith and Parker, Reissner and Pagan also focus on the temporal dimension of engagement, and 
consider how managerial engagement strategies are perceived and experienced by employees. Uniquely, the authors show the influence of communication strategies on individuals' lived experiences of engagement and how these can serve to develop new cultural understandings over time.

The final three articles in this issue provide important contributions to the literature on engagement in reporting quantitative data through a positivist lens, building on a range of debates within the psychological engagement paradigm. These papers are important, in that they extend prior quantitative research through the application of novel methodologies and insight into debates relevant to the HRM field.

Arnold Bakker and Despoina Xanthopoulou's article draws on the job demandsresources model to explore the charismatic leadership and creativity of female school principals. Survey data from 84 head teachers and 190 of their direct reports show that the personal resources, including resiliency, and the engagement of the head teachers, were positively associated with creative performance and charismatic leadership as rated by the teachers. This paper makes a unique contribution to the engagement literature by examining the antecedents and outcomes of engagement within one study, and by demonstrating for the first time a link between engagement, creativity and leadership.

In their article, Chris Rees, Kerstin Alfes and Mark Gatenby turn their attention to the link between employee voice and engagement, within the framework of social exchange theory. Drawing on self-report survey data from 2310 employees in two UK-based service sector firms, Rees and colleagues found positive relationships between perceived employee voice, the employee-line manager relationship, trust in senior managers and engagement. This paper bridges debates within the HRM and engagement fields and raises important questions about employee experiences of voice from a unitarist perspective, which has also been the subject of Townsend et al.'s (2013) study.

Finally, Zeynep Yalabik, Patchara Popaitoon, Julie Chowne and Bruce Rayton focus on the link between engagement and a range of outcome variables in a cross-lagged survey involving 199 bank clerical workers surveyed at two time points. They discovered that job satisfaction and commitment predicted levels of engagement (rather than vice versa), and that engagement mediated the relationship between satisfaction and commitment, intent to quit, and job performance. Through its longitudinal design, this article contributes to our understanding of the temporal ordering of engagement in relation to its antecedents and outcomes, and establishes the discriminant validity of engagement from job satisfaction and affective commitment. In its longitudinal design, it complements the earlier papers by Arrowsmith, Francis and colleagues.

Taken together, these papers constitute the first special issue within an HRM journal dedicated to the topic of employee engagement. With their diversity of findings and plurality of perspectives, the authors point to a rich field of scholarly interest that holds great promise for researchers and practitioners alike. There are a number of emerging themes arising from these papers that are of particular note.

First, contributions from scholars working within a positivist and psychological paradigm are using increasingly sophisticated statistical techniques to analyse ever more complex, multi-layered and longitudinal survey data-sets. These are able to shed a more nuanced light on engagement, its antecedents and outcomes, enriching our knowledge of how individuals' experiences of engagement are associated with other attitudinal variables and organisational experiences such as leadership, as well as individuals' subsequent behaviours and intentions, thus advancing the reflexive process of 'fixing' engagement within a conceptual space. 
Second, the articles written from a critical, discourse-analytic and employee-centred perspective start to open up the debate within the HRM field concerning the status of the engagement construct in relation to existing paradigms and conceptualisations of the employment relationship. Here, scholars have approached engagement from a similar stance to the practitioner viewpoint as a form of individualised high-commitment workforce strategy, rather than regarding engagement as an experienced psychological state. This has enabled contributors to explore the nexus between organisational engagement aspirations and the lived experience of organisational actors, raising perennial questions of the legitimacy of a unitarist frame of reference, the potential associations between engagement, the fragmentation of the employment relationship and work intensification, and the location of engagement within its organisational and wider societal and institutional settings. These contributions show in a nuanced way that engagement has been 'bent' through its appropriation to managerialist agendas, and 'stretched' in its meaning away from being an individual state of mind to encompass workforce strategies and dialogic practice.

\section{Engagement and HRM: where next?}

In addition to making a strong contribution to debates around engagement, the papers in this special issue raise further questions about the future of scholarly endeavour within the engagement field, and point the way to important gaps in knowledge which are yet to be addressed.

At a general level, the authors question how engagement initiatives relate to the current global economic and political climate of adversity and cost control (Francis, Ramdhony, Reddington and Staines 2013). Arrowsmith and Parker, and Jenkins and Delbridge point to the conflation of engagement with performance management, with the approaches of managers, and the experiences of employees, leaning towards a 'hard' approach to HRM, the humanistic rhetoric notwithstanding.

Implicit within several of the contributions is also the issue of how engagement, broadly defined, is understood and interpreted across differing cultures (Kelliher, HopeHailey and Farndale 2013; Rothmann 2013). Future research in the field that focuses on how engagement is framed within societal, cultural and economic settings would help to shed light on these issues. From a psychological perspective, greater understanding of these cross-cultural issues would enhance efforts to develop generalisable measures of engagement.

Several of the papers in the special issue suggest that there are further questions that remain unanswered about the development, implementation and experience of engagement initiatives - 'doing' engagement and 'being' engaged. Most of the research on engagement that has hitherto taken place within the psychology field has focused on micro-level attitudinal variables, 'being' engaged, and has not yet considered how senior managers and HRM professionals go about developing and seeking to embed engagement programmes, 'doing' engagement, nor has it sought to evaluate employees' lived experience of these. Authors contributing to this special issue argue that more research is needed on this important area that is of central concern within the HRM field. For example, what engagement strategies are most successful at raising engagement levels? Crucially, the authors question whether engagement, as part of the managerialist project, is always benign for workers, and future research could examine the enactment of engagement programmes and practices alongside workers' responses and experiences.

We also propose that further studies are needed to explore the interplay between the internal contextual environment within organisations, managerial constraints and 
engagement; Jenkins and Delbridge draw attention to the contested nature of engagement practices and highlight the bounded rationality of managers seeking to embed engagement. Beyond this, there are concerns over the unitarist foundations of the engagement construct. A number of the contributors show how the enactment of engagement within organisational settings is bound up with fundamental issues of control and consent, and more studies that examine engagement as a contested managerial strategy would be welcome.

The papers by Reissner and Pagan, and Francis and colleagues, extend the debate on engagement into the field of communication, discourse and conversational practice. To the best of our knowledge, these are the first articles to have done this, and so further research building on these important themes would be welcome. For example, future observational research could examine the detailed conversations between employees and managers to shed light on the micro-level processes that constitute the lived experience of engagement.

There is also a dearth of knowledge about how engagement is related to other ongoing debates within the HRM field. For instance, Arrowsmith and Parker raise the question of the association between engagement and collectivist forms of representation, a theme further explored by Townsend et al. (2013). What is the interplay between individually oriented engagement initiatives and the role of trade unions and other representative bodies? More studies that build on the work of Arrowsmith and Parker, and Townsend et al. (2013), would be welcome.

A further significant gap in knowledge in both the engagement and the HRM fields concerns gender and diversity. As these two fields converge, addressing this gap becomes more pressing. Halford and Strangleman (2009) suggest even that sociological studies of work in general have privileged the male industrial worker over work done by women. Feminist scholars have remained largely silent on the central debates within the HRM field (Truss 1999). Future research could explore the state of engagement as experienced by male and female employees, those from different ethnic groups and those with disabilities, the micro-level experiences of engagement strategies and initiatives on the part of diverse workers, and the outcomes of high and low levels of engagement for these groups.

From a methodological perspective, the contributions to this special issue illustrate a broad array of approaches to understanding engagement. This plurality is to be welcomed. We are witnessing growing sophistication in the quantitative methods used within the psychology field to address engagement. Papers in this Issue use multi-level, multiinformant methodologies to tap into the causal relationships between engagement, its antecedents and consequences. Further studies adopting similar approaches would be welcome, in order to show how engagement is situated within its nomological network (Parker and Griffin 2011). Studies that combine quantitative and qualitative approaches would be particularly welcome, as these could lead to generalisable findings alongside deep insights into the context of engagement.

Little is known about engagement at the group or team level, and explorations of this would be a fruitful avenue for future research. For example, it may be that engagement or disengagement is 'contagious' within teams and work groups, perhaps arising from the relational context (Kahn and Heaphy 2013), and uncovering the micro-level processes that give rise to this would be an important addition to knowledge in the field.

Finally, we return to the general debate about the link between HRM, engagement and performance at the level of the individual and the firm. This is clearly a fruitful avenue for future research endeavour, particularly since there is evidence that engagement may be associated not only with raised levels of performance but also with enhanced well-being (Schaufeli 2013), addressing the concern that the two cannot go hand-in-hand. More 
studies that examine this potential linkage from both a quantitative and a qualitative perspective, adopting positivist, as well as more critical methodologies would be welcome. The contributions to this special issue suggest that it is at present too early to assert definitively that there is a link between HRM, engagement and performance. Alongside the perennial theoretical and methodological questions raised about the HRMperformance link (Guest 2011), the introduction of such a contested construct as employee engagement into the equation, rather than providing a welcome clarity, may instead simply serve to muddy the waters further still.

\section{Conclusion}

A significant body of research has emerged on the topic of engagement within the psychology field over the past 20 years whose relevance to HRM is only now starting to be acknowledged. As engagement makes the disciplinary leap, it is being interrogated by scholars with diverse perspectives in industrial relations, work sociology, discourse analysis, HRM and critical management studies, who are raising new and challenging questions about the status of the engagement construct and its relevance within the context of wider debates about the employment relationship (Purcell 2013; Townsend et al. 2013; Jenkins and Delbridge 2013).

This special issue contributes to these emerging concerns with seven articles that advance scholarship at the nexus of HRM and employee engagement. Their diverse perspectives on 'doing' engagement and 'being' engaged highlight the way that engagement has been subject to 'fixing, shrinking, stretching and bending' as the construct develops. Crucially, the authors challenge the view that engagement can invariably be a 'win-win' scenario for both employees and employers as the micro-level enactment of engagement within the wider organisational context forefronts the ideological divide, power relationships and contextual constraints experienced in 'doing' engagement and 'being' engaged.

There is a clear need for further research that advances our understanding of the psychological processes underpinning engagement, the precise meaning and status of the engagement construct, the lived experiences of 'doing' engagement and 'being' engaged, issues of power and engagement, and the micro- and macro-level processes round the enactment of engagement within organisational settings. We currently lack a 'big science' (Wall and Wood 2005) of engagement, but the contributions to this special issue make significant strides by highlighting some of the fundamental issues raised at the nexus between employee engagement on the one hand and HRM on the other.

\section{Acknowledgements}

The authors thank the 36 independent reviewers who contributed to this special issue for their helpful, timely and constructive feedback on submissions. The authors also gratefully acknowledge the support of the ESRC for their grant for the seminar series, 'Employee Engagement, Organisational Performance and Individual Well-being: Exploring the Evidence, Developing the Theory' (RES-451-26-0807). Rick Delbridge also acknowledges the support of the ESRC through the Skills, Knowledge and Organizational Performance Research Centre (RES-557-28-5003).

\section{References}

Alfes, K., Shantz, A.D., Truss, C., and Soane, E.C. (2013), 'The Link Between Perceived Human Resource Management Practices, Engagement and Employee Behaviour: A Moderated Mediation Model,' The International Journal of Human Resource Management, 24, 330-351. 
Alfes, K., Truss, C., Soane, E.C., Rees, C., and Gatenby, M. (in press), 'The Relationship Between Line Manager Behavior, Perceived HRM Practices and Individual Performance. Examining the Mediating Role of Engagement,' Human Resource Management.

Allen, D.G., Shore, L.M., and Griffeth, R.W. (2003), 'The Role of Perceived Organizational Support and Supportive Human Resource Practices in the Turnover Process,' Journal of Management, $29,99-118$.

Biswas, S., Varma, A., and Ramaswami, A. (2012), 'Linking Distributive and Procedural Justice to Employee Engagement Through Social Exchange: A Field Study in India,' The International Journal of Human Resource Management, 24, 1570-1587.

Boselie, P., Dietz, G., and Boon, C. (2005), 'Commonalities and Contradictions in HRM and Performance Research,' Human Resource Management Journal, 15, 67-94.

Christian, M.S., Garza, A.S., and Slaughter, J.E. (2011), 'Work Engagement. A Quantitative Review and Test of its Relation with Task and Contextual Performance,' Personnel Psychology, 64, $89-136$.

Conway, E., and Monks, K. (2009), 'Unravelling the Complexities of High Commitment: An Employee-Level Analysis,' Human Resource Management Journal, 19, 140-158.

Delbridge, R., and Keenoy, T. (2010), 'Beyond Managerialism?' The International Journal of Human Resource Management, 21, 799-817.

Den Hartog, D.N., Boselie, P., and Paauwe, J. (2004), 'Performance Management. A Model and Research Agenda,' Applied Psychology, 53, 556-569.

Francis, H.M., Ramdhony, A., Reddington, M., and Staines, H. (2013), 'Opening Spaces for Conversational Practice: A Conduit for Effective Engagement Strategies and Productive Working Arrangements,' The International Journal of Human Resource Management, 24, $2713-2740$, this issue.

George, J.M. (2011), 'The Wider Context, Costs, and Benefits of Work Engagement,' European Journal of Work \& Organizational Psychology, 20, 53-59.

Guest, D.E. (2011), 'Human Resource Management and Performance: Still Searching for Some Answers,' Human Resource Management Journal, 21, 3-13.

Guest, D.E. (2013), 'Employee Engagement: Fashionable Fad or Long-Term Fixture?' in Employee Engagement in Theory and Practice, eds. C. Truss, K. Alfes, R. Delbridge, A. Shantz, and E.C. Soane, London: Routledge.

Hakanen, J.J., and Schaufeli, W.B. (2012), 'Do Burnout and Work Engagement Predict Depressive Symptoms and Life Satisfaction? A Three-Wave Seven-Year Prospective Study,' Journal of Affective Disorders, 141, 415-424.

Halbesleben, J.R.B. (2011), 'The Consequences of Engagement: The Good, the Bad and the Ugly,' European Journal of Work \& Organizational Psychology, 20, 68-73.

Halford, S., and Strangleman, T. (2009), 'In Search of the Sociology of Work: Past, Present and Future,' Sociology, 43, 811-828.

Harter, J.K., Schmidt, F.L., and Hayes, T.L. (2002), 'Business-Unit-Level Relationship Between Employee Satisfaction, Employee Engagement, and Business Outcomes: A Meta-Analysis,' Journal of Applied Psychology, 87, 268-279.

Huselid, M.A. (1995), 'The Impact of Human Resource Management Practices on Turnover, Productivity, and Corporate Financial Performance,' Academy of Management Journal, 38, $635-672$.

Jenkins, S., and Delbridge, R. (2013), 'Context Matters: Examining "Soft" and "Hard" Approaches to Employee Engagement in Two Workplaces,' The International Journal of Human Resource Management, 24, 2670-2691, this issue.

Kahn, W.A. (1990), 'Psychological Conditions of Personal Engagement and Disengagement at Work,' Academy of Management Journal, 33, 692-724.

Kahn, W.A., and Heaphy, E.D. (2013), 'Relational Contexts of Personal Engagement at Work,' in Employee Engagement in Theory and Practice, eds. C. Truss, K. Alfes, R. Delbridge, A. Shantz, and E.C. Soane, London: Routledge.

Keenoy, T. (2013), 'Engagement: A Murmuration of Objects,' in Employee Engagement in Theory and Practice, eds. C. Truss, K. Alfes, R. Delbridge, A. Shantz, and E.C. Soane, London: Routledge.

Kelliher, C., Hope-Hailey, V., and Farndale, E. (2013), 'Employee Engagement in Multinational Organisations,' in Employee Engagement in Theory and Practice, eds. C. Truss, K. Alfes, R. Delbridge, A. Shantz, and E.C. Soane, London: Routledge. 
Kuvaas, B. (2008), 'An Exploration of How the Employee-Organization Relationship Affects the Linkage Between Perception of Developmental Human Resource Practices and Employee Outcomes,' Journal of Management Studies, 45, 1-25.

Lombardo, E., Meier, P., and Verloo, M. (2010), 'Discursive Dynamics in Gender Equality Politics: What about "Feminist Taboos",' European Journal of Women's Studies, 17, 105-123.

MacLeod, D., and Clarke, N. (2009), Engaging for Success: Enhancing Performance Through Employee Engagement, London: Office of Public Sector Information.

Maslach, C., and Leiter, M.P. (1997), The Truth About Burnout: How Organizations Cause Personal Stress and What to do About it, San Francisco, CA: Jossey-Bass.

Parker, S., and Griffin, M. (2011), 'Understanding Active Psychological States: Embedding Engagement in a Wider Nomological Net and Closer Attention to Performance,' European Journal of Work and Organizational Psychology, 20, 60-67.

Purcell, J. (2013), 'Employee Voice and Engagement,' in Employee Engagement in Theory and Practice, eds. C. Truss, K. Alfes, R. Delbridge, A. Shantz, and E.C. Soane, London: Routledge.

Rothmann, S. (2013), 'Employee Engagement in a Cultural Context,' in Employee Engagement in Theory and Practice, eds. C. Truss, K. Alfes, R. Delbridge, A. Shantz, and E.C. Soane, London: Routledge.

Saks, A.M. (2006), 'Antecedents and Consequences of Employee Engagement,' Journal of Managerial Psychology, 21, 600-619.

Salanova, M., and Schaufeli, W.B. (2008), 'A Cross-National Study of Work Engagement as a Mediator Between Job Resources and Proactive Behaviour,' The International Journal of Human Resource Management, 19, 116-131.

Schaufeli, W.B. (2013), 'What is Engagement?' in Employee Engagement in Theory and Practice, eds. C. Truss, K. Alfes, R. Delbridge, A. Shantz, and E.C. Soane, London: Routledge.

Schaufeli, W.B., Salanova, M., Gonzalez-Roma, V., and Bakker, A.B. (2002), 'The Measurement of Engagement and Burnout: A Two Sample Confirmatory Factor Analytic Approach,' Journal of Happiness Studies, 3, 71-92.

Shuck, B. (2011), 'Integrative Literature Review: Four Emerging Perspectives of Employee Engagement: An Integrative Literature Review,' Human Resource Development Review, 10, 304-328.

Shuck, B., and Reio, T.G. (2011), 'The Employee Engagement Landscape and HRD: How Do We Link Theory and Scholarship to Current Practice?' Advances in Developing Human Resources, $13,419-428$.

Shuck, B., and Rocco, T. (2013), 'HRD and Employee Engagement,' in Employee Engagement in Theory and Practice, eds. C. Truss, K. Alfes, R. Delbridge, A. Shantz, and E.C. Soane, London: Routledge.

Snape, E., and Redman, T. (2010), 'HRM Practices, Organizational Citizenship Behaviour, and Performance: A Multi-Level Analysis,' Journal of Management Studies, 47, 1219-1247.

Soane, E.C. (2013), 'Leadership and Employee Engagement,' in Employee Engagement in Theory and Practice, eds. C. Truss, K. Alfes, R. Delbridge, A. Shantz, and E.C. Soane, London: Routledge.

Storey, J. (1989), 'Human Resource Management in the Public Sector,' Public Money and Management, 9, 19-24.

Townsend, K., Wilkinson, A., and Burgess, J. (2013), 'Routes to Partial Success: Collaborative Employment Relations and Employee Engagement,' The International Journal of Human Resource Management, early online publication, DOI: 10.1080/09585192.2012.743478.

Truss, C. (1999), 'Human Resource Management: Gendered Terrain?' The International Journal of Human Resource Management, 10, 180-200.

Truss, C., Alfes, K., Delbridge, R., Shantz, A., and Soane, E.C. (2013a), Employee Engagement in Theory and Practice, London: Routledge.

Truss, C., Alfes, K., Delbridge, R., Shantz, A., and Soane, E.C. (2013b), 'Introduction,' in Employee Engagement in Theory and Practice, eds. C. Truss, K. Alfes, R. Delbridge, A. Shantz, and E.C. Soane, London: Routledge.

Truss, C., Mankin, D., and Kelliher, C. (2012), Strategic Human Resource Management, Oxford: Oxford University Press.

Wall, T.D., and Wood, S.J. (2005), 'The Romance of Human Resource Management and Business Performance, and the Case for Big Science,' Human Relations, 58, 429-462. 
Watson, T.J. (2010), 'Critical Social Science, Pragmatism and the Realities of HRM,' The International Journal of Human Resource Management, 21, 915-931.

Wright, P.M., Snell, S.A., and Dyer, L. (2005), 'New Models of Strategic HRM in a Global Context,' The International Journal of Human Resource Management, 16, 875-881.

Youssef-Morgan, C.M., and Bockorny, K.M. (2013), 'Engagement in the Context of Positive Psychology,' in Employee Engagement in Theory and Practice, eds. C. Truss, K. Alfes, R. Delbridge, A. Shantz, and E.C. Soane, London: Routledge. 